\title{
A mímesis do Quinteto Armorial: uma busca pela autenticidade da música brasileira ${ }^{1}$
}

\author{
Nívea Lins Santos ${ }^{2}$
}

\begin{abstract}
Resumo: Este artigo teve por finalidade analisar, sob o conceito de mímesis, as referências artístico-culturais do grupo musical Quinteto Armorial e sua atuação em prol da construção de certa "autêntica música brasileira", em meio à modernidade. Sob a orientação de Ariano Suassuna, a paisagem sonora do quinteto foi uma resposta a um determinado momento histórico brasileiro que parecia colocar em xeque perspectivas e práticas mais tradicionais sobre laços identitários (tanto nacional quanto nordestino). Sendo assim, buscou-se refletir como o grupo atuou mimeticamente tendo por cenário a relação entre tradição e modernidade no contexto brasileiro.

Palavras-chave: Quinteto Armorial. Mímesis. Música brasileira. Modernidade. Tradição.
\end{abstract}

The mimesis of the Armorial Quintet: A quest for the authenticity of Brazilian music

Abstract: The purpose of this article was to analyze, under the concept of mimesis, the artistic-cultural references of the musical group Armorial Quintet and its performance in favor of the construction of a certain "authentic Brazilian music", in the midst of modernity. Under the guidance of Ariano Suassuna, the quintet's sound landscape was a response to a particular Brazilian historical moment that seemed to put more traditional perspectives and practices on identity ties (both national and northeastern) in check. Thus, it was sought to reflect how the group acted mimetically by setting the relationship between tradition and modernity in the Brazilian context.

Keywords: Armorial Quintet. Mímesis. Brazilian music. Modernity. Tradition.

\footnotetext{
${ }^{1}$ Recebido em 31/05/2017 e aprovado em 25/08/2017.

${ }^{2}$ Doutoranda em História e Cultura Social no Programa de Pós-graduação da UNESP/Franca, desenvolvendo a tese "Brasilindia: o mosaico sonoro de Alberto Marsicano (1984-2009)", com financiamento da Coordenação de Aperfeiçoamento de Pessoal de Nível Superior (CAPES). Integra o Grupo de Estudos Culturais (GECU) da UNESP/Franca.
} 
$|114|$

A mímesis do Quinteto Armorial:...

La mimesis del Quinteto Armorial: Una búsqueda de la autenticidad de la música brasileña

Resumen: Este artículo tuvo por finalidad analizar, bajo el concepto de mímesis, las referencias artístico-culturales del grupo musical Quinteto Armorial y su actuación en pro de la construcción de cierta "auténtica música brasileña", en medio de la modernidad. Bajo la orientación de Ariano Suassuna, el paisaje sonoro del quinteto fue una respuesta a un determinado momento histórico brasileño que parecía poner en jaque perspectivas y prácticas más tradicionales sobre lazos identitarios (tanto nacional como nordestino). Siendo así, se buscó reflejar cómo el grupo actuó mímicamente teniendo por escenario la relación entre tradición y modernidad en el contexto brasileño.

Palabras-clave: Quinteto Armorial. Mímesis. Música brasileña. Modernidad. Tradición.

O Quinteto Armorial (1970-80) ${ }^{3}$, pertencente ao Movimento Armorial de Ariano Suassuna, foi um grupo de música de câmara surgido em Recife, cuja intenção era fortalecer a música brasileira baseada nas ditas raízes da tradição popular (com destaque para aquelas vinculadas à região nordestina), de modo a dialogálas com elementos da tradição erudita europeia, uma vez que havia o entendimento de que ambos os universos culturais eram heranças fundantes da música brasileira, que precisariam ser rememoradas constantemente, ainda mais em tempos de modernidade.

Vale lembrar que, durante o século XX, associar a ideia de brasilidade a lugares mais "intocados" pela modernidade foi uma prática recorrente entre intelectuais e artistas brasileiros direcionados à consolidação da ideia de nação por meio do protagonismo do Estado. A partir da década de 1970, no entanto, houve uma maior consolidação do mercado de bens culturais. Dessa forma, de interesse do poder público, mas agora

${ }^{3}$ Os músicos integrantes do Quinteto Armorial eram os seguintes: Antônio José Madureira na viola sertaneja, tambor e zabumba; Edilson Eulálio no violão, ganzá e matraca; Antônio Carlos Nóbrega de Almeida no violino, rabeca e caixa; Fernando Torres Barbosa no marimbau e tambor; Egildo Vieira no pífano e prato. Quanto aos álbuns, eles produziram quatro no total: Do romance ao galope nordestino, de 1974; Aralume, de 1976; Quinteto Armorial (com participação da Orquestra Romançal Brasileira), de 1978; e, por fim, Sete flechas, de 1980. 
também das inciativas privadas, a integração da nação se orientou a partir da expansão modernizadora dos meios de comunicação de massa no país ${ }^{4}$. Sentindo ainda a repercussão do milagre brasileiro, a política fiscal de incentivos e isenções facilitou ainda mais a entrada de capital estrangeiro, o que favoreceu o estímulo ao consumo, principalmente de bens materiais duráveis e industrializados. A modernidade brasileira, porém, não resolveu diversas contradições e impasses sociopolíticos, uma vez que a modernização chegou ao país, mas não conseguiu nos tirar da situação de nação dependente das principais economias mundiais ${ }^{5}$.

Perante esse panorama dos anos 70, o Quinteto Armorial (assim como o próprio Movimento Armorial), interpretou com criticidade os efeitos da modernização no Brasil, pois considerou uma faceta imperialista a presença de estrangeirismos (especialmente aqueles vindos dos EUA), importados a partir dos meios de comunicação de massa em ampla expansão internacional. No que se refere à música, de acordo com os armorialistas, a música popular veiculada pelas grandes indústrias fonográficas era fundamentalmente comercial e, por isso, deveria ser problematizada, pois não se voltaria para questões de "autenticidade" e de "memória nacionais". Se o caráter insólito do mundo moderno estabelecia novas relações (mais dinâmicas e mesmo contraditórias), a relação entre tradição e modernidade foi pauta de debate para vários artistas e intelectuais, sendo os armorialistas alguns deles. Segundo o Movimento Armorial, alguns elementos da modernidade tinham o potencial de colocar em risco características mais tradicionais, podendo desconfigurar, portanto, nossa identidade

${ }^{4}$ Para mais informações, ver: Ortiz (1989).

${ }^{5}$ Para mais informações, ver, por exemplo, Hollanda (2004).

${ }^{6}$ Ariano Suassuna chamava de imperialismo americano essa presença em larga escala dos valores culturais e dos ditames políticos e econômicos dos Estados Unidos em território brasileiro. Saber mais em: Medeiros (2013) e Suassuna (2008). 
$|116|$

A mímesis do Quinteto Armorial:...

(tanto nacional quanto nordestina), e não valorizar devidamente as nossas heranças.

Sem defender um regionalismo militante, o Quinteto Armorial elegeu o Nordeste como um importante espaço simbólico das raízes do povo brasileiro, pois havia a ideia de que as regiões Sul e Sudeste se encontravam em um processo mais acelerado de desenvolvimento industrial, urbano e cosmopolita e, então, não conseguiam preservar tradições mais remotas, ao contrário do Norte e Nordeste, que se inseriam nesse processo de modo mais lento e mantinham mais intactas tais raízes. Faz-se necessário destacar que os integrantes do Movimento Armorial eram originários da região nordestina e demonstravam certa resistência aos acontecimentos culturais e econômicos das grandes capitais do Sudeste e do Sul. Eles defendiam uma arte popular nordestina (particularmente rural e sertaneja) como símbolo de uma brasilidade autêntica.

Sendo assim, o Quinteto Armorial buscou desenvolver uma paisagem sonora ${ }^{7}$ que transportasse afetivamente o ouvinte brasileiro às suas origens históricas, de modo a fortalecer

\footnotetext{
${ }^{7}$ De acordo com Schafer (2001), o conceito de paisagem sonora consiste em abarcar tanto a experiência humana em apreender o ambiente sonoro que o cerca (incluindo os sons da natureza, os ruídos da cidade, etc.), quanto reconhecer os impactos históricos e culturais sobre a música em diferentes momentos da história da música ocidental. A ideia de uma paisagem sonora nordestina (ver: Ventura, 2007) é retomada neste artigo, pois o Quinteto Armorial se valeu de uma estética dita nordestina como base fundamental para a sua concepção artística. É evidente que o espaço cultural nordestino foi permeado por construções imaginárias e imaginadas, as quais devem ser analisadas criticamente. Nesse sentido, entendemos que o quinteto buscou reforçar a magnificência de tal espaço, para se evitar sentimentos de inferioridade nordestina e "[...] valorizar no âmbito dos sentidos e dos afetos aquilo que, no entender dos armorialistas, sempre fez do nordestino sentir e ser o que é; não como um sujeito imutável ou passivo, mas como um sujeito consciente de si, [...] que [...] sempre fora parte integrante fundamental da identidade brasileira e que, portanto, não deveria em nenhum momento cair em esquecimento/menosprezo nacional"' (SANTOS, 2015, p. 159).
} 
tanto a identidade nacional, quando a identidade nordestina, com a finalidade de que tais origens fossem reconhecidas, bem como engrandecidas. Compreende-se que a atuação armorial se orientou a partir de uma mímesis mais aristotélica, pois houve a projeção de uma arte, uma imagem mimética, enquanto representação mais próxima daquilo que seria a sustentação mais genuína da noção de brasilidade.

O conceito de mímesis deriva da filosofia clássica da Grécia Antiga e que, perante o desenvolvimento da racionalidade ocidental ao longo dos séculos, apresentou diversas formas interpretativas (sobretudo em questões estéticas e políticas). “Os gregos clássicos pensam sempre a arte como uma figuração enraizada na mímeses, na representação, ou, melhor, na 'apresentação' da beleza do mundo [...]; a música é o exemplo privilegiado de mímeses, sem que seja imitativa no nosso sentido restrito" (GAGNEBIN, 2005, p. 80).

As reflexões de Platão e Aristóteles muito serviram de fundamentação para tal conceito ${ }^{8}$, bem como para estudos posteriores, ainda que ambos os filósofos tenham divergido acerca do mesmo. Segundo Platão, a maneira como é constituída a "apresentação" da beleza do mundo, ou melhor, a mímesis, deve ser uma pauta importante dentro de um aparelho político, pois ela possui potencial persuasivo, que estimula aspectos mais "sensíveis" do indivíduo, podendo enganá-lo, e, então, não contribuir para o desenvolvimento de uma comunidade justa. Platão buscava traduzir e reproduzir um paradigma ideal de educação moral e cívica, pois o encanto da mímesis (muito associado ao universo das artes), somado à ingenuidade dos ouvintes, se não tivessem a devida atenção dos políticos, seriam capazes de colocar em risco o equilíbrio político-social. Por isso sua desconfiança à prática mimética.

${ }^{8}$ Saber mais em: Aristóteles (1998) e Platão (2000). 
$|118|$

A mímesis do Quinteto Armorial:...

Com efeito, a imagem mimética é, primeiro, definida na sua falta essencial de ser: em relação à ideia, à forma primeira que os objetos concretos reproduzem inabilmente, a imagem poética ou plástica não é mais que cópia [...]. Talvez possamos dizer que a mímeses possui essa força não apesar de não participar do ser verdadeiro, mas, mais secretamente, justamente porque ela não participa dele, porque ela aponta para o engodo, para a mentira, para a ilusão e a falta. [...]. Sabendo da força das imagens, Platão tenta domar, controlar a produção dessas imagens, impondo-lhe normas éticas e políticas (GAGNEBIN, 2005, p. 81-82).

Por outro lado, para Aristóteles, a mímesis diz respeito a uma forma privilegiada de aprendizado, uma vez que não incentivaria um desvio moral do indivíduo; ao contrário, estimularia imagens de similaridade metafórica por meio da linguagem e, como consequência disso, produziria graça e momentos prazerosos. Por exemplo, associar a beleza de uma flor com a da pessoa amada não significa que a imagem de uma é concretamente igual a da outra, mas que a partir da linguagem elas podem ser relacionadas metaforicamente na abordagem estética do interlocutor. "O impulso mimético está na raiz do lúdico e do artístico. Ele repousa sobre a faculdade de reconhecer semelhanças e produzi-las na linguagem" (GAGNEBIN, 1993, p. 91).

Importante ressaltar que dentro da perspectiva da Antiguidade Clássica, a mímesis - a despeito de tais objeções aqui brevemente mencionadas - pertencia, intrinsecamente, ao mundo mítico e ritualístico, ao qual o ser humano ainda se baseava em instintos impulsivos de medo e encanto pela natureza, sendo esta, até então, compreendida como indomável. O caráter mítico se fazia presente justamente por tal natureza ser indomesticável e misteriosa. A partir do momento em que se iniciou o processo de desenvolvimento da racionalidade ocidental, o ser humano buscou se livrar do medo do indomável - e, portanto, do mundo mágico -, uma vez que a racionalidade trouxe a promessa 
de dominação da natureza (externa e interna ao indivíduo), o que séculos depois culminou no pensamento Iluminista, nos anseios dos tempos modernos.

Ao longo do século $X X$, a sensação de que a construção de nossa nacionalidade não havia se consolidado plenamente teve ápices de protagonismo dentro dos debates sobre identidade e cultura brasileira. Desse modo, as definições de cultura brasileira foram marcadas por reflexões divergentes, em que a reflexão entre modernidade e tradição se mostrou acirrada e característica fundamental perante nossa compreensão sobre o "ser autenticamente brasileiro". O Movimento Armorial, visando um reestabelecimento de vínculos e de tradições, atuou sob os efeitos de tal sensação.

A partir de tais apontamentos, vejamos, por conseguinte, como se construiu a prática mimética do Quinteto Armorial. Um dos eixos centrais do quinteto (nesse ponto fortemente influenciado pelo Ariano Suassuna) se direcionou para a relação entre o apolíneo e o dionisíaco, pois se percebeu nela uma maneira de compreender o processo de formação do povo brasileiro, ou melhor, do "ser castanho" tal qual Suassuna tanto defendia em suas reflexões. Ariano Suassuna se apropriou da ideia de união dos contrários personificada nas duas divindades Apolo e Dioniso, com o objetivo de reconciliar as dicotomias do "ser brasileiro".

Para Nietzsche, em $A$ origem da tragédia, tais divindades representariam uma espécie de "antagonismo natural", em que um necessariamente traz consigo o outro, mesmo que indiretamente, já que eles se desafiam e se estranham o tempo todo. Porém, em busca do equilíbrio natural da vida (e por que não dizer da arte), por vezes elas se apaziguam, propiciando espaço para uma criação inovadora e interpretativa sobre o mundo 9 .

${ }_{9}^{9}$ Segundo Nietzsche, "[...] é, pois, às suas duas divindades das artes, a Apolo e Dionisos, que se refere a nossa consciência do extraordinário antagonismo, tanto de origens como de fins, que existe no mundo grego entre a arte plástica ou apolínea e a arte sem formas ou musical, a arte dionisíaca. Estes dois instintos impulsivos andam lado a lado e na maior parte do tempo em guerra 
$|120|$

A mímesis do Quinteto Armorial:...

Partindo desse princípio nietzschiano, Ariano Suassuna aprofundou esse pensamento em contexto brasileiro: para ele era preciso reviver os antagonismos fundantes de nossa identidade, pois eles tinham sido essenciais, criativos e inovadores para a diversidade sociocultural brasileira, bem como marcados pela tendência assimiladora e unificadora de contrários:

Se examinarmos o povo brasileiro do ponto de vista de seu comportamento social, de sua Psicologia, de sua História, de sua Arte, de sua Literatura, encontraremos sempre essa tendência assimiladora e unificadora de contrários - o espírito mágico e fantástico complementado pelo realismo crítico e satírico; a metamorfose da florescência e da decomposição; cotidiano e quimera; a presença do dionisíaco buscando o gume contido e a garra da forma despojada do apolíneo; violência e mau-gosto do popular e refinamento do erudito; o épico e a introspecção individual chegando esta às vezes à idolatria do $\mathrm{Eu}$; o lirismo personalista e o social coletivo; as convenções e a festa; o Belo e o Feio; espírito profético e comportamento orgiático; o vegetal da Mata e o deserto do Sertão; o Trágico e o Cômico; a aldeia e o mundo; otimismo e pessimismo; embriaguez da Vida, o pó e a cinza da Morte; o Dramático e o Humorístico; o fogo da destruição e o culto da florescência e ressurreição (Ariano Suassuna apud VENTURA, 2007, p. 56-57).

aberta, mutuamente se desafiando e excitando para darem origem a criações novas, cada vez mais robustas, para com elas perpetuarem o conflito deste antagonismo que a palavra "arte", comum dos dois, consegue mascarar, até que por fim, devido a um milagre metafísico da 'vontade' helênica, os dois instintos se encontrem e se abracem para, num amplexo, geralmente a obra superior que será ao mesmo tempo apolínea e dionisíaca [...]" (NIETZSCHE, 2008, p. 19). 
Dessa maneira, Suassuna interpretou uma reconciliação entre o apolíneo e o dionisíaco, sendo a música uma expressão privilegiada para a efetiva aliança de "contrários" no ato da criação e representação do real. Como bem discorreu o filósofo Roberto Machado, em Apolo há um processo de criação do indivíduo, ou seja, de um princípio de individuação/consciência de si mesmo, na sua forma mais plena possível; "[...] Apolo é o brilhante, o resplandecente, o solar" (MACHADO, 2005, p. 7) e representa a medida e a serenidade. Já em Dioniso há o oposto desse processo, pois se trata de um sentimento místico de unidade e, portanto, de abandono de si mesmo; “[...] a experiência dionisíaca é a possibilidade de escapar da divisão, da individualidade, e se fundir ao uno, ao ser; é a possibilidade de integração da parte na totalidade" (MACHADO, 2005, p. 8).

A ordem e a desordem, o racional e o místico, personificados respectivamente por Apolo e Dioniso, apazíguam-se na tentativa de atingir a mais íntima essência da vida humana; a partir de tal ótica eles não são simplesmente adversos, mas sim, necessariamente, complementares um do outro, pois buscam uma espécie de equilíbrio cósmico, cuja relação se faz por meios mágicos e naturais. A partir disso, nota-se que Suassuna se aproximou dessa perspectiva e, então, frequentemente associou o "sublime" e o "profano" sob um olhar que não nega os "contrários", uma vez que "[...] o Romanceiro popular do Nordeste, como toda a Arte e toda a Literatura mais autenticamente brasileiras, tem muito do espírito dialético do Barroco" (SUASSUNA, 2008, p. 141). A ideia de fusão dos "contrários" no Brasil, presente na representação mimética entre o apolíneo e o dionisíaco, muito se concretizou por meio do Barroco brasileiro (sendo este visto uma importante herança identitária), colaborando - na visão de Suassuna - para a formação do "ser castanho".

O termo "castanho" foi desenvolvido em sua Tese de Livre-docência A onça castanha e a Ilha Brasil: uma reflexão sobre a cultura brasileira, de 1976, em que a "onça castanha" representava literária e simbolicamente o caráter mestiço do povo brasileiro, 
$\mid 122$ |

A mímesis do Quinteto Armorial:...

sendo o sertão nordestino o lugar social que mais preservava as heranças culturais da mestiçagem entre o indígena, o negro e o europeu. No pensamento de Suassuna, o litoral sempre fora um território mais suscetível à presença internacional, então, mais movediço e não confiável quanto à preservação dos laços identitários ditos mais genuínos e tradicionais. Para ele, a miscigenação brasileira se fez de certo modo harmoniosa ${ }^{10}$ e deu origem ao povo castanho; sendo assim, é válido destacar que Suassuna se aproximou de muitas perspectivas de Gilberto Freyre, não negando que por ele tinha grande admiração. No excerto a seguir, Suassuna, além de admitir a influência de Freyre, explicou o porquê de sua resistência ao modernismo pós-1922 e de sua busca pelo retorno à tradição:

[...] a influência de Gilberto Freyre veio a se concretizar não mais diretamente em minha arte mas em minhas ideias, agora através da tradição, o que tem, aliás, se acentuando nos últimos anos. Como ele - mais do que ele, talvez -, antipatizo terrivelmente com o movimento modernista. Minha simpatia, no âmbito deste movimento, vai mais para aqueles que renegaram o fundamental das ideias de 22, como acontece, a meu ver, com Carlos Drummond de Andrade. Eu detesto aquilo que se chama "arte de vanguarda". Não dá dois anos, a arte de vanguarda vira retaguarda. Esta aversão levou-me à procurar a tradição, voltando-me

\footnotetext{
${ }^{10}$ Embora a ideia de um Brasil mestiço seja muito lembrada por causa dos estudos de Gilberto Freyre, ela é anterior a este autor. Desde o final do século XIX, em meio às teorias evolucionistas e à campanha pela abolição no Brasil, a mestiçagem serviu de fundamento para forjar "unidades" e "autenticidades" em prol de um Brasil dito próspero e civilizado. Houve uma produção intelectual significativa, mesmo que não homogênea, transcorrida para o início do século XX e direcionada a construir por vezes uma imagem harmônica da mestiçagem (a exemplo do escritor Olavo Bilac). Faz-se necessário dizer que tal imagem deve ser problematizada, uma vez que as hierarquias sociais e raciais não se dissiparam, de modo a conduzir ações discriminatórias - nos âmbitos do político e do cultural - em defesa do embranquecimento da nação.
} 


\begin{abstract}
para aqueles mestres que são "eternamente nossos contemporâneos". Eu sentia e sinto que é preciso reencontrar os tesouros da tradição mediterrânea que a arte contemporânea renega (SUASSUNA, 2008, p. 55).
\end{abstract}

Cabe frisar que ao negar a arte de vanguarda e qualquer produção moderna que se pautasse na inserção de "imperialismos externos descaracterizantes", Suassuna não realizou simplesmente uma busca pelo passado, mas sim um reencontro com o perene em todas as expressões artístico-culturais. Isto significa que elencar e, consequentemente, valorizar alguns nomes consagrados, tais como Camões, Tolstoi, Dostoievski, Balzac, José Lins do Rego, Guimarães Rosa, Euclydes da Cunha, entre outros, ocorreu pelo fato de que Suassuna percebeu neles alguns princípios e valores universais - para além de suas respectivas nacionalidades e temporalidades - pelos quais, então, mereciam ser rememorados (cf. SANTOS, 2015, p. 77).

Ele argumentou que muito do perene poderia ser encontrado nos períodos Clássico e Barroco. Nesse processo de seleção sobre o que deveria ou não ser resgatado, a Antiguidade Clássica - com suas epopeias e tragédias gregas - e a cultura medieval - com seu canto gregoriano, trovadores e cavalarias também foram referências para o Movimento Armorial. Porém, no discurso de Suassuna, não houve a proposta de "medievalizar" ou "europeizar" a cultura brasileira (bem como a nordestina), mas sim de encontrar em tais referências alguns legados que teriam sido importantes para a construção da noção de brasilidade ao longo do tempo. As xilogravuras dos folhetos nordestinos, por exemplo, apresentavam mimeticamente reis, guerreiros, profetas, seres encantados, místicos e religiosos correspondentes, de certo modo, ao mundo místico medieval, como também ao universo tragicômico dos ditos clássicos da Grécia Antiga. "Para mim, porém", diz Suassuna, 
$|124|$

A mímesis do Quinteto Armorial:...

[...] o mais importante de tudo era que a xilogravura popular nordestina me encantava tanto quanto aquelas artes românticas e pré-renascentistas a que me referi. [...] Entenda-se de uma vez por todas que quando falo nessas coisas não é pregando uma impossível e ridícula cruzada no sentido de "medievalizar" ou "europeizar" a cultura brasileira; é apenas por reconhecer e reencontrar tais elementos e semelhanças na cultura brasileira do povo. [...] Meu encanto pelo teatro de Aristófanes, de Sófocles, de Plauto, de Shakespeare, de Goldoni, de Calderón, de Gil Vicente, ou pela novela picaresca, pela de cavalaria, pela de Cervantes e de Boccaccio vinha, mais, era do fato de eu reencontrar em tudo isso um espírito correspondente ao do Sertão, do Nordeste e do Brasil, o espírito dos romanceiros e dos espetáculos populares nordestinos; as mesmas lutas sangrentas; o épico; as vinditas familiares; os casos de crime, de amor e de ciúme; as fomes das grandes secas e epidemias, com seus cortejos de miséria, sofrimento e morte; as legendas; a crítica social; as burlas; o ódio; o riso violento e desmedido - tudo isso alçado, porém às alturas do poético, do trágico e do cômico, pela força arrebatadora e transfiguradora do mítico (SUASSUNA, 2008, p. 214-215).

Tendo em vista tais referências plurais, o processo de criação musical, que os armorialistas idealizaram, foi uma forma de retomar a discussão - ainda não resolvida - de como se elaborar uma produção autenticamente nacional ${ }^{11}$. Nesse sentido, para eles era preciso reestabelecer vínculos sociais entre arte e sociedade, pois dadas as rápidas transformações

11 Os ideais armorialistas não obtiveram uma aceitação unânime, principalmente em Pernambuco. Em Olinda, no ano de 1968, foi lançado o 1- Manifesto Tropicalista Nordestino escrito por Jomard Muniz de Britto, Aristides Guimarães e Celso Marconi, que se mostrou o contrário do discurso defendido pelo Armorial. Isso porque para outros artistas, também engajados na discussão sobre cultura brasileira, o Armorial tinha um olhar engessado sobre cultura popular. Para mais informações, ver: Teles (2012) e Vargas (2007). 
da modernidade, tais vínculos corriam o risco de se dissiparem e de comprometerem os sensos mais remotos de identidade.

A presença de uma sonoridade mais ritualística no Quinteto Armorial foi outra característica mimética e estratégica para se resgatar uma expressão artística mais artesanal (que visasse o reestabelecimento de tais vínculos), que se pretendia, portanto, na contramão das padronizações estéticas cada vez mais imperiosas em tempos de mundialização da cultura. Os músicos do quinteto atuaram como "artesãos", na medida em que buscaram uma produção mais holística de suas obras musicais, pois o artesão possui a noção de todo o processo de construção daquilo que desenvolve. Somado a isso, os armorialistas tiveram suas referências de inspiração que deveriam ser preservados (como já mencionados anteriormente). É evidente que essa intenção artesanal não se concluiu por completo, ou seja, ela teve apenas alguns momentos de certo protagonismo. Isso porque na modernidade não há como se reconciliar - ainda mais de forma apaziguadora - os processos envolvidos entre indústria cultural e as retomadas idealizadas do pré-moderno. Sempre haverá um aspecto tensionado não resolvido.

No seu fazer mimético, o Quinteto Armorial retomou (como referência artístico-cultural) a tragédia grega, o imaginário medieval, bem como os contrastes rebuscados do Barroco e o rigor formal do Classicismo. Mas outras influências também foram relevantes, tais como Erik Satie. Segundo Antônio Madureira,

\footnotetext{
Eu tenho como ícone Erik Satie [...], que foi de encontro a toda uma postura erudita europeia. Suas peças são "miniaturas", muito simples, e um pianista que toca Beethoven não respeita isso. Mas nem por isso ela deixa de ser uma música poderosa, uma música de muitas ideias, uma música que eu não troco por aquele monte de acordes e toda aquela bravura de Beethoven (apud VENTURA, 2007, p. 170).
}

A partir desse relato, é possível notar certa contradição do Quinteto Armorial, pois ao mesmo tempo em que não houve 
uma retomada do caráter exuberante das tendências românticas em seu fazer musical, a proposta de exaltação de uma comunidade (característica do Romantismo) em busca da consolidação de uma identidade (fosse ela nacional ou e/ou regional) foi também um parâmetro fundamental em seu discurso. Satie foi uma referência para Madureira por prezar por certa simplicidade harmônica nas composições. Quando Madureira, e mesmo Suassuna, encontra inspiração nos períodos Clássico e Barroco, isso se deu mais pelo fato de eles valorizarem a objetividade formal desses períodos (cf. SANTOS, 2015, p. 79).

Além disso, entre os armorialistas houve a percepção de que o cantar e o tocar da cultura popular não eram práticas que exigissem um alto grau de erudição (se comparada às dimensões da música de concerto). Elas apresentariam certa simplicidade na maneira de expressar suas ideias e sentimentos no aspecto harmônico, mas justamente por isso seriam riquíssimas em "clareza" formal, pois tocariam fundamentalmente na dita essência do nosso povo, não possuindo maiores interferências externas que as descaracterizariam (cf. idem, p. 80).

Pode-se perceber que, aliada a essa visão de busca pela essência, houve também uma espécie de mímesis do campo/ do sertão, isto é, um enaltecimento dos sons, dizeres, crenças e rituais de todo o ambiente "natural" do sertanejo (tanto geográfico quanto sociocultural), uma vez que o sujeito interiorano seria aquele quase intocado pelas descaracterizações da modernidade. Tal essência, portanto, estaria ainda muito ligada ao mundo mágico e ritualístico, cujos vínculos entre arte e sociedade permaneceriam inexoravelmente conectados.

Relevante mencionar que a música pertencente à tradição nordestina - que tanto o quinteto exaltou - não era tão racionalizada ao ponto de desenvolver-se perfeitamente sob os parâmetros do sistema tonal, até mesmo porque parte da estética musical nordestina (seu martelo agalopado, galope à beira-mar, 
sextilha, quadrão, etc.) teve a cultura moçárabe como herança ${ }^{12}$. $\mathrm{O}$ uso de repetição em temas melódicos, em detrimento do aprimoramento harmônico tonal, proporciona ao ouvinte a sensação de se estar presenciando um ritual. Note-se, até mesmo, um efeito de hipnose a fim de que ele atinja o sublime e o transcendental (cf. SANTOS, 2015, p. 82).

Esse efeito de hipnose ritualístico é uma característica fundamental da música modal pré-moderna, que muito faz uso das repetições melódica e rítmica, e possui desenvolvimento harmônico rudimentar, ou mesmo inexistente ${ }^{13}$. Essa repetição proporciona um caráter místico à música, pois esta possui um papel social bem definido de representação e relação com tudo \}o que não se compreende racionalmente. Há de se reforçar que essa música é anterior ao processo da racionalização moderna e, muitas vezes, foi interpretada ao longo da história da música ocidental como "primitiva" e/ou "exótica" (idem, p. 82).

O Quinteto Armorial, ao se valer de dinâmicas modais, coletivas, hipnóticas, ritualísticas e repetitivas (rítmicas e melódicas), estimulou uma escuta musical não somente apreciativa, no sentido concertista do termo. Interpretamos o seu material sonoro como uma tentativa mimética de levar o ouvinte ao sertão, às heranças identitárias do "ser brasileiro", e também de fazer com que o mesmo pense com o corpo, ou melhor, tenha uma experiência musical coletiva que lhe remeta sensorialmente às sonoridades e vivências mais remotas. Os ritmos tradicionalmente identificados como sendo nordestinos, a exemplo do coco, baião, frevo, maracatu, embolada, entre outros, trazem a dança como

\footnotetext{
${ }^{12}$ Sobre a herança da cultura moçárabe na cultura popular nordestina, ver: Soler (1995).

${ }^{13}$ Conforme José Miguel Wisnik, “[...] o mundo modal é em sua grande parte o mundo dessas formações sociais resistentes à mudança e a todo tipo de evolução, mantendo-se na repetição ritual de suas fórmulas e suas escalas recorrentes, o que o faz furtar-se ao ritmo progressivo da história, até que o capitalismo o desintegre, modernamente" (WISNIK, 2011, p. 77).
} 
elemento essencial de suas práticas (uma audição pelo corpo) ${ }^{14}$, e que, portanto, foram retomados de alguma forma pelo Quinteto Armorial.

Diante de uma regressão da audição cada vez mais perceptível em tempos modernos, o Quinteto Armorial pode ter sido uma alternativa (ainda que não resolvida) para se quebrar esta lógica a partir da reconexão com o universo do sagrado, do mítico e do coletivo. Ouvir com o corpo é trazer à lembrança o movimento da relação entre música e ouvinte; este que não só ouve, mas participa ativamente da prática musical, por meio de cantorias conectadas às danças, cortejos, preces, marchas, etc. $\mathrm{O}$ avanço da racionalização capitalista diante da história da civilização ocidental foi permeado por um processo de reificação do ser humano, solapando muito dessa prática mais holística da música. É significativo perceber que Ariano Suassuna orientou o Quinteto Armorial a partir também da negação da coisificação humana.

A crítica de Suassuna à transformação do ser humano em objeto, para fins mercadológicos massivos, é perceptível na sua arte e concepção de cultura. Por isso que encontramos nele e, consequentemente, no Quinteto Armorial, uma valorização do ser humano enquanto sujeito, enquanto indivíduo consciente de si no tempo e no espaço histórico. A paisagem sonora produzida pelo quinteto, portanto, foi a consequência de uma prática mimética e de mediação sobre vivências identitárias, mnemônicas e afetivas acerca do nordestino e do brasileiro, enquanto um sujeito ativo no seu próprio fazer artístico, cultural e histórico, bem como daquilo que podia ser considerado sua identidade.

\footnotetext{
${ }^{14}$ Segundo Albuquerque Junior (2006, p. 156), o nordestino tradicionalmente escuta música com o corpo, e não simplesmente a partir de uma apreciação auditiva e imóvel do caráter musical. Tendo em vista tal análise, é evidente que não se deve corroborar com estereótipos limitantes e generalizadores; porém, o autor está se referindo mais especificamente ao fato da cultura popular nordestina, muito vinculada ao universo do meio rural, fomentar a relação entre música e dança.
} 


\section{Referências}

ALBUQUERQUE JUNIOR, Durval Muniz de. A invenção do nordeste e outras artes. $3^{\underline{a}}$ ed. Recife: FJN; Massangana / São Paulo: Cortez, 2006.

ARISTÓTELES. Política (Tradução de Roberto Leal Ferreira). 2ª ed. São Paulo: Martins Fontes, 1998.

GAGNEBIN, Jeanne Marie. Lembrar escrever esquecer. São Paulo: Ed. 34, 2006.

GAGNEBIN, Jeanne Marie. Sete aulas sobre linguagem, memória e história. 2ª ed. Rio de Janeiro: Imago, 2005.

HOLLANDA, Heloísa Buarque de. Impressões de viagem: CPC, vanguarda e desbunde: 1960/70. 5aㅡ ed. Rio de Janeiro: Aeroplano, 2004.

MACHADO, Roberto. Nietzsche e a polêmica sobre o nascimento da tragédia. Rio de Janeiro: Jorge Zahar Ed., 2005.

NIETZSCHE, Friedrich. A origem da tragédia. 13ª ed. São Paulo: Centauro, 2008.

ORTIZ, Renato. A moderna tradição brasileira: cultura brasileira e indústria cultural. 2ª ed. São Paulo: Brasiliense, 1989.

PLATÃO. A República (Tradução de Carlos Alberto Nunes). $3^{\underline{a}}$ ed. Belém: EDUFPA, 2000.

SANTOS, Nívea Lins. O galope nordestino diante do parque industrial: o projeto estético do Quinteto Armorial no Brasil moderno. Dissertação de Mestrado em História. Franca: UNESP, 2015.

SCHAFER, Raymond Murray. A afinação do mundo - uma exploração pioneira pela história passada e pelo atual estado do mais negligenciado aspecto de nosso ambiente: a paisagem sonora. São Paulo: UNESP, 2001. 
| 130 |

A mímesis do Quinteto Armorial:...

SOLER, L. Origens árabes no folclore do sertão nordestino. Florianópolis: Ed. UFSC, 1995.

SUASSUNA, Ariano. Almanaque armorial (Organização de Carlos Newton Júnior). Rio de Janeiro: José Olympio, 2008.

SUASSUNA, Ariano. O Movimento Armorial, Revista Pernambucana de Desenvolvimento, Recife, v. 4, n. 1, p. 39-65, jan./jun. 1977.

TELES, José. Do frevo ao manguebeat. $2^{\underline{a}}$ ed. São Paulo: Ed. 34, 2012.

VARGAS, Herom. Hibridismos musicais de Chico Science \& Nação Zumbi. Cotia: Ateliê, 2007.

VENTURA, Leonardo Carneiro. Música dos espaços: paisagem sonora do nordeste no movimento armorial. Dissertação de Mestrado em História. Natal: Universidade Federal do Rio Grande do Norte, 2007.

MEDEIROS, Wandecy. Entrevista de Ariano Suassuna a Wandecy Medeiros, 4 maio 2013. Disponível em: <http://www.patosonline. com/post.php?codigo=33916>. Acesso em: 05 nov. 2017.

WISNIK, José Miguel. O som e o sentido: uma outra história das músicas. $2^{\underline{a}}$ ed. São Paulo: Companhia das Letras, 2011. 